\title{
14. Business benefits from keeping codes of ethics up to date
}

\author{
Michael Bowern and Oliver K Burmeister \\ Australian Computer Society, Charles Sturt University
}

\section{Introduction}

The greater the extent to which a code of ethics is kept up to date, the better is the case that it benefits business to abide by that code. In 2010 the Australian Computer Society (ACS) updated its code of ethics after an extensive review, including national focus groups with members, and international input. Its last update, in 1985, predates most of the recent industry advancements. It was undertaken prior to advances and innovations, such as object-oriented techniques, the Internet and nanotechnology, of the last two decades. Industry currency of the ACS code is important if it is to have endorsement and adherence by Information and Communications Technology (ICT) professionals.

Almost every professional society has a code of ethics. Sometimes it is called a code of professional conduct, or behaviour, or something similar. In each situation it is a standard for the personal conduct of members of that professional society. In the ICT industry there are some professional societies that do not have such a code and, for the majority that do have one, questions have been raised about their efficacy.

Are such codes enforceable? Does the public hold ICT professionals accountable, based on such codes? Are codes simply weighty statements that serve no practical purpose? Why should the business community pay attention to such codes? This chapter attempts to answer questions such as these in two ways.

One way is by making a case for having a professional code of ethics. Many books have been written on ethics and, within many of these, the purpose of such a code is defined. That is not what this chapter means, however, by making a case for a code of ethics. Instead, a business case is proposed. A few years ago, environmental issues were given lip-service, but essentially ignored, whereas, today, companies see a business case for taking environmental issues seriously. Similarly, a business case can be made for creating and enforcing adherence to an up-to-date code of ethics for the ICT industry. 
The second way such questions are answered is through making the case for renewing codes of ethics on a regular basis. Just as ICT changes over time, so a code of ethics in ICT should be kept current. Codes should stay current and relevant to professionals working in the industry. Some aspects of a code may not change frequently, others should. For instance, since its inception, the ACS code of ethics has had 'Honesty' as a guiding principle. The way in which this concept has been interpreted, however, in professional ICT behaviour over the past 40 years has changed. It is not envisaged that a future ACS code will call on ICT professionals to be dishonest, but the way in which honesty is practiced in the workplace can subtly change over time.

This chapter begins by making a business case for the ACS code of ethics, and then goes on to reflect on the current process of renewing this code. For the latter, the case is made that such codes ought to undergo a major review at least every decade, with minor reviews possible in the intervening years.

\section{A business perspective}

In Australia the ACS, in collaboration with the Australian Research Council, funded a major industry review of ICT ethics (Lucas \& Weckert, 2008). That report has many findings, one of which, the most pertinent to this chapter, revealed that ACS members have a poor understanding of issues relating to professionalism and ICT ethics. The contention presented here is that concerns such as these are best addressed by making a business case for professional/ ethical behaviour.

Richard Lucas and John Weckert used evidence from surveys and interviews to show that many people in the ICT industry do not see themselves as ICT 'professionals'. The term 'professional' is poorly understood in the ICT industry, even amongst members of the ACS.

This is an important finding, because it shows that there is a need for the ACS to raise the profile of professionalism. Arguably, the ACS has already taken significant steps in this regard. The Lucas and Weckert report showed, however, that these efforts have not, to date, yielded the desired results. New ways of marketing professionalism need to be created. Professionals have special responsibilities and public accountabilities, be they in ICT or another industry such as medicine or law.

Inherent in the promotion of professionalism is the promotion of a code of professional behaviour and, in this regard, the ACS code of ethics is the focus of this chapter. 


\section{Professionalism defined}

The Australian Council of Professions (ACP), of which the ACS is a member, is a peak body for professional societies in Australia. Trading as Professions Australia, it states:

A profession is a disciplined group of individuals who adhere to ethical standards and hold themselves out as, and are accepted by the public as possessing special knowledge and skills in a widely recognised body of learning derived from research, education and training at a high level, and who are prepared to apply this knowledge and exercise these skills in the interest of others.

It is inherent in the definition of a profession that a Code of Ethics governs the activities of each profession. Such codes require behaviour and practice beyond the personal moral obligations of an individual. They define and demand high standards of behaviour in respect to the services provided to the public and in dealing with professional colleagues. Further, these codes are enforced by the profession and are acknowledged and accepted by the community (ACP, 2009).

Using a detailed definition of 'profession' avoids the confusion of 'professional' being used as an adjective as well as a noun and, more importantly, identifies a number of special conditions which help to distinguish a 'profession' from an 'occupation'. From the definition above, a professional is a member of a disciplined group of individuals. The ACS is one such group, which represents the people working in the ICT industry, but, unlike doctors and lawyers, Australia does not require ACS members to be registered or licensed, and membership of the ACS is voluntary.

In 2000 the ACP recognised members of the ACS as professionals. It was the first time this had happened outside software engineers being able to claim to be professionals through membership of the Institute of Electrical and Electronics Engineers (IEEE). At the time the ACS promoted this development widely and significantly raised its membership numbers. However, the Lucas and Weckert (2008) report shows that the momentum was not sustained and that, even today, some ACS members do not understand what professionalism means.

\section{The business case}

The ACS believes that the society's code of ethics has two main roles. First, to promote professional behaviour by members of the society. Second, to promote to the government and business sectors, the value of employing people who 
practise the values of the ACS code. This section presents a business case for the second role and, in so doing, reflects the community expectations identified in the previous definition of a profession.

A decade ago, very few businesses realised that being eco-friendly could deliver a commercial competitive advantage; nowadays, that proposition is uncontentious. Promoting professionalism should be positioned in a similar way, so that it quickly becomes commercially desirable, and uncontentious, for professional people in the ICT industry to behave in a manner consistent with a code of ethics.

If a business makes clear that being eco-friendly meets its corporate objectives, it follows that it will recruit and value staff who help it to conduct its activities in that way. Similarly, if a business makes clear that being professional has marketable commercial advantages, it will give priority in its recruiting to people who manifest this value, and will send a signal to the community that employing professional people has value.

The other side of the coin is for the community to demonstrate that professional conduct is valued to the point where preference will be given to those businesses and individuals who behave in that way.

To support the previous points, the ACS needs to promote the value of professional conduct to both consumers and suppliers. That requires the society to devise examples and scenarios to illustrate how the code of ethics works in particular situations, and highlights how resolving an issue in an ethical way confers tangible benefit on the consumer. The outcome ought to be that consumers of ICT demand that suppliers practise what the ACS code of ethics requires.

Professional principles would apply to the teams and organisations developing systems that are critical, in terms of safety, the environment, and other social aspects. At one level, this approach would ensure a reduction in the public's regular infuriation with technology, by supplying products and services that meet consumers' reasonable expectations without faults or failures, or undisclosed constraints, expenses or risks.

Professional principles would be promoted as the reference point for safe and professional practices, and would be publicised on the ACS website, and other sites dedicated to this issue.

From an ACS internal perspective, it should develop a marketing strategy that involves corporate professional partnerships in which each corporate partner undertakes to encourage its relevantly qualified staff to practise its code of ethics for the benefit of its customers, and to join the ACS. 
The aim is for ACS membership to become a proxy for certification to which an individual has committed, and who practises the type of conduct that is espoused by their professional society. By creating a demand for people who conduct themselves in that way, the value proposition of ACS membership commensurately increases.

The ACS should be working with national, state and local governments, and other areas of the public sector, to help them lead by example and make compliance with the ACS code of ethics mandatory in the ICT areas of government agencies, whether or not their technical staff are ACS members.

\section{The approach in the Australian pharmaceutical industry}

Some ideas and direction for the ACS could be gained by considering aspects of the Australian pharmaceutical industry, in which there is regulation of some of the products and activities of that industry.

In Australia there is a federal government requirement that the manufacturing processes of pharmaceutical products comply with standards addressing good manufacturing practice (GMP), or similar quality requirements. Regulation is based on risk mitigation, so complementary medicines (such as vitamins) are not regulated to the same extent as prescription medicines, or devices that are invasive to humans and/or include software, for example automatic drugdelivery systems. These may also be regulated against other product-specific standards.

The benefits to pharmaceutical businesses of compliance with their professional code are well recognised. These benefits include risk management and mitigation, and consumer confidence in products through compliance with professional and product standards.

Pharmaceutical businesses enforce their standards within and beyond their industry. A condition of registration of every new medicine is that its marketing and promotional literature complies with a specific code of conduct. This code of conduct is maintained by an industry organisation, the members of which include the manufacturers of many Australian pharmaceutical products. The code covers all aspects of marketing, including the relationships with health professionals such as doctors, dentists, and pharmacists. There is an industry committee to investigate complaints, identify breaches of the code, and impose fines or other disciplinary actions. The government condition attached to product registration makes some requirements of the code of conduct applicable to companies that are not members of the industry organisation. 
Obviously, there are differences between the ICT industry and the pharmaceutical industry, and the purpose of this section is not to argue for government regulation of all ICT products. As a starting point, however, it is advocated that those people and organisations engaged in the development and maintenance of public-sector ICT projects should be required to observe the ACS code of ethics. Also, the ACS disciplinary committee should have jurisdiction to hear and determine complaints against both ACS members and non-members in those circumstances.

\section{The benefit to business}

As described below, a code of ethics typically consists of a) a code of conduct - how a person conducts him or herself in an ethical manner, and b) a code of practice - how a person carries out his or her specific tasks and responsibilities. In a business, such a code of ethics should not exist in isolation, it should be part of a business integrity system, in which the code is supported by policies, staff training, and disciplinary processes. In turn, the integrity system should relate to the systems for quality and other management functions used by the business. These other systems could describe how the business addresses the management of finance, risk, occupational health and safety, and the environmental aspects of its operation. It is preferable that these are not individual systems, but are integrated into one business management system. In effect, the code of practice is complementary to this business management system.

In the 1980s many businesses recognised that by adopting the techniques of quality management and process improvement they would improve their profitability, and gain a competitive advantage through increased customer satisfaction and improved products and services. It has been argued that qualitymanagement activities will maximise the long-term value of a business (Foley et al, 1997). Value means more than just financial value. Other values could be a safe and healthy work environment, the provision of adequate training and tools to employees, an eco-friendly workplace, and a work culture that recognises a job well done. Likewise, a focus on the quality of products would be of value to suppliers, who might then focus on the quality of their own products, and to customers.

A business which instils these types of value by focusing on its quality processes is behaving ethically, and reflects the existence of a code of practice for quality management. If a business gains benefits by following good qualitymanagement practices, it would also see that it could benefit by following codes of practice for occupational health and safety, and the environmental aspects of 
its business, for example. By establishing codes of practice for work activities, a business has already adopted one half of its code of ethics. The next step is to adopt a code of conduct, which is available from the ACS for ICT businesses.

\section{Renewal of the ACS Code of ethics}

A code of ethics has several major functions. These include the requirement to articulate ethical standards of the profession; to educate practitioners and the public about ethical obligations; and to provide guidance to resolve ethical quandaries (Burmeister, 2000; Burmeister \& Weckert, 2003; Coldwell, 2008). In order to fulfil these functions satisfactorily it is important that the code is reviewed on a regular basis to keep it relevant, and up to date.

\section{What is included in a code of ethics?}

There are numerous terms in the literature for professional codes of 'ethics'. This chapter follows the guidance of the International Federation for Information Processing (IFIP) (Berleur et al, 2004), in discussing two types of codes.

The first type, is a code of 'ethics/conduct', which has a set of high-level statements, concerning such issues as honesty and integrity. This code governs 'how the person to whom it applies conducts him or herself in an ethical manner' (Berleur et al, 2004: 11). To avoid confusion, this type will be referred to as the code of conduct in the rest of this chapter.

The second type of code refers to a 'code of practice' for professionals, which 'governs how the person to whom it applies carries out his or her work technically' (Berleur et al, 2004: 11). This code includes a set of detailed statements related to the professional's particular occupational environment. These statements of practice are more specific and more likely to change over time, than are the conduct statements.

Typically, a professional society would define both types of code for its members in a single document. One example for ICT is the standard for teaching and practicing software engineering, published by the ACM and IEEE-Computer Society (CS) (SECEPP, 1999). In this chapter, reference to a 'code' or a 'code of ethics' means a document that includes both types of code, covering conduct and practice. Other references will be made to the specific type of code under consideration, for example a 'code of practice'. 


\section{To benefit business, professional codes should address current business challenges}

The development of any technology can provide a range of new business opportunities, and this is particularly so with respect to ICT. Just as businesses periodically re-evaluate their strategic direction, so professional societies need to ensure the currency of their codes to the business communities they serve.

A simple example of this could be if a number of companies developed technology and software to use the wide range of personal information on social networking sites in ways that were not originally intended. The ACS code would apply to the professionals in these organisations who were members of the society. Some of these members might feel that their code did not sufficiently cover the ethical issues of information security and privacy arising from this new business approach, and so they make the ACS aware of their dilemma. The ACS should then review the relevant areas of the code in the light of this new use of technology. They might decide that the information security and privacy provisions in the code were sufficient, but that it needed additional material on whistleblower action and protection.

In a domain that changes as frequently as that of ICT, a change in work practice, or the advent of some new technology, should not of itself constitute grounds for changing a code of ethics. Examples of the types of change that could warrant reviewing a code include the growth of the Internet, the increased use of outsourcing and off-shoring, and the arrival and impact of micro/nano computing.

Codes, however, cannot be reviewed with every change in technology that occurs.

To avoid ineffective continuous code reviews, procedural guidelines are needed within a professional society that ensure regular review of its code or codes. How frequently should such a review be undertaken? Given the logistical difficulties involved, and based on observations of previous changes to codes in Australia and the United States, Bowern et al (2006) proposed that codes ought to be reviewed at least every 10 years. The ACM code underwent significant reviews in 1992 and again in 1998, but not since. The ACS code was reviewed in 1975, and again in 1985, but not since then. The review procedure also ought to allow for reviews that are determined by major technology changes. The advent of a biological computer implanted in the brain might be the sort of thing that justifies immediate code review rather than waiting a prescribed period of time.

Changes to codes of ethics have been motivated by a desire to include their expanded sense of professional responsibility and behaviour occasioned by some technological advances (Gotterbarn, 1996). Other changes have been made to include an aspirational component in the code (Burmeister, 2008). 
Why aspirational? To appeal for ethical behaviour when enforcement is not possible. In medicine and law, a breach of the code of ethics can mean loss of ability to practice one's profession. Not so in the ICT industry. An ACS member can be held accountable through the ACS disciplinary procedures. But 80 per cent of ICT practitioners in Australia are not ACS members. Also, a member facing ACS disciplinary procedures could simply resign. Then s/he can continue to behave unethically; they simply can no longer claim to be an ICT 'professional', which is a right that the ACP (2009) has restricted to use only by ACS members. This ACP restriction, however, is not legally binding. There is nothing directly that the ACS can do to prevent non-ACS members calling themselves ICT professionals.

Instead, the ACS should raise the standard of what it means to be an ICT professional in Australia. The ACP recognition provides the ACS with an ideal foundation from which to redefine ICT professionalism. Given that the ACP requires professionals to adhere to a code of ethics, this further provides the ACS with the opportunity to define ICT professionalism in Australia in terms that closely align with its own code of ethics, further strengthening its position in Australia as the arbiter of professional behaviour. The Lucas and Weckert (2008) report clearly showed that the efforts of the ACS to do this have not been successful to date. The ACS has to devise new strategies to market the benefits of its professional code to the ICT business community.

Gotterbarn (2000), writing about experiences in the development of two codes of ethics in the United States, found that a critical issue is that of specificity; that is, how prescriptive and detailed the code should be. One approach to specificity is in the clauses of the code itself. Generally, the code of conduct does not change over time, but changes in the activities and products of the ICT industry practice mean that the application of the code, as seen in the code of practice, is different. The task of maintaining the code is simpler where the code of conduct is separate from the code of practice, and it is much harder where there is no clear distinction in the document between conduct clauses and practice clauses.

\section{The relevance of the ACS code of ethics to business}

The joint ACM/IEEE software engineering code of ethics has been endorsed and adopted by over 50 companies in the United States. One reason for its acceptance may be that its most recent review included wide involvement of the ICT business community. In contrast the current review of the ACS code was only carried out among ACS members. About six per cent of ACS members are from academia, a tiny percentage are student members or retirees, and the rest are all members working in the ICT industry. Although the majority of participants in the review were from the business community, they participated as individuals, not directly as representatives of their respective businesses. In some of the focus groups, however, the comments made were specifically relevant to businesses. 
If an ICT company decides to adopt the business case for an ethical approach described above, it will be necessary to define the company's policy on ethics, adopt an appropriate code of ethics, provide training in this code, and start to develop an ethical culture in the company. The ACS code of ethics would be a good starting point for these activities. For additional support in these activities, the company could become a professional partner with the ACS. This initiative by the ACS provides companies that become partners with a number of benefits, including professional development support, recruitment of qualified professional people, recognition in the ICT industry, and attractive professional indemnity insurance rates. Currently, the ACS has over 170 professional partners.

\section{Structure of the ACS code}

An earlier review of the renewal process for the ACS code of ethics (Bowern et al, 2006) noted that it comprises two sections. The first section is a simple policy statement plus a declaration of six values and ideals, which are then expanded into the second section, a detailed set of 37 statements or 'Standards of conduct'. This code of ethics is defined as part of the ACS national regulations, to emphasise the importance of the code, and to ensure its prominence in the ACS body of documentation.

Supplementary to the code of ethics is the code of professional conduct and professional practice. This code was developed to provide more practical guidance in the day-to-day activities of ICT professionals. It is not part of the national regulations, which means that it is easier to amend and update. Changes to the national regulations require a vote by the national congress, followed by a vote by all members of the ACS. This has implications for future amendments to the codes. Figure 1 illustrates these various codes.

\begin{tabular}{|c|c|c|c|c|}
\hline \multicolumn{2}{|c|}{ National regulations } & & \multirow{2}{*}{\multicolumn{2}{|c|}{$\begin{array}{l}\text { Code of professional } \\
\text { conduct and } \\
\text { professional practice }\end{array}$}} \\
\hline \multicolumn{2}{|c|}{ Clause } & & & \\
\hline 4. & ACS code of ethics & & \multirow{3}{*}{\multicolumn{2}{|c|}{ Introduction }} \\
\hline 4.1 and 4.2 & Policy statement & & & \\
\hline 4.3 & Values and ideals & & & \\
\hline 4.4 to 4.10 & $\begin{array}{l}\text { Standards of } \\
\text { conduct }\end{array}$ & $\begin{array}{l}\text { There is overlap } \\
\text { between the standards } \\
\text { of conduct and the code } \\
\text { of professional conduct }\end{array}$ & Section A & $\begin{array}{l}\text { Code of } \\
\text { professional } \\
\text { conduct }\end{array}$ \\
\hline \multicolumn{2}{|c|}{$\begin{array}{l}\text { There is no identified code of } \\
\text { professional practice in the national } \\
\text { regulations }\end{array}$} & & $\begin{array}{l}\text { Sections B } \\
\text { to } L\end{array}$ & $\begin{array}{l}\text { Code of } \\
\text { professional } \\
\text { practice }\end{array}$ \\
\hline
\end{tabular}

Figure 1: The 'conduct' overlap 
The code of professional conduct is intended as a guideline for acceptable personal conduct for each IT professional practicing in the industry and, as such, it is complementary to the values and ideals and the standards of conduct. There is some overlap between the standards of conduct and the codes of conduct.

All reviews of the ACS code of ethics, including the current one, have been limited to the left side of Figure 1. That is, they are limited to the values and ideals and their associated standards of conduct.

The code of professional practice is intended as a guideline for acceptable methods of practice within the ICT industry. The guideline is generic and addresses a range of aspects of product life cycle, and acquisition, development, implementation and support processes. The code of professional conduct and professional practice has not been updated since its adoption by the society.

Engineering organisations in Australia tend to have their own values and obligations, although some of these companies may also practise the professional code of the Institution of Engineers Australia. Similarly, the six values and ideals of the ACS code of ethics could form the basis of the values and obligations of ICT businesses in Australia. That would, in effect, create closer ties between business values and those of the ACS code, and possibly bring some businesses in closer contact with the ACS, as mentioned previously in relation to the professional partners program.

\section{Guidance and education}

Further work is needed to identify how the ACS code can best provide guidance and education to its members. Current attempts by the ACS Committee on Computer Ethics CCE to accomplish this are mainly through better communication and publicity of the code to ACS members.

Some members of the CCE have produced a set of case studies related to each of the clauses in the ACS code, which have been publicised to members via the ACS website, and used for teaching in some tertiary institutions. Also, since late 2004, the CCE has arranged for a regular column in Information Age, the ACS bimonthly magazine for members and other professionals in the industry. The column seeks to promote the professional code, and discuss the ethical aspects of current ICT news items. The case studies are one source of material for these articles.

Advice should be provided on how the code would apply to the wide range of ACS members, some of whom are not directly involved in systems development; for example, ICT professionals dealing directly with customers, such as some 
empirical software engineers. If the ACS code is to cater to the widest possible interpretation of 'ICT professional', it must be examined for its applicability to all aspects of the profession. An excellent example has been set through the ACM/IEEE software engineering code, that has been adopted by the ACS for its members who are software engineers (Davidson, 2004). The adoption of the software engineering code is another contribution to the specificity of supplementary ACS codes.

\section{Updating the ACS code of ethics}

The review process for the ACS Code of Ethics, which was initially described in the Bowern et al 2006 report, has now been completed. Following international advice, as detailed in the earlier report, an extensive consultative process was followed, particularly with ACS membership. As with the 1985 review, this involved focus groups at each of the ACS branches across the country. The Western Australian branch was the exception at this stage, as this branch was reserved to provide a final review of the completed, new code. A preliminary report was submitted to the ACS management committee, which foreshadowed the recommendations of the review.

The final step in the renewal process was the drafting of the new document, which meant carefully capturing members' views about individual clauses in the code of ethics. Contradictory suggestions were resolved, and some clauses were reworded to support the updated code. This was completed in late 2009, after which the Western Australian branch focus group provided a further opportunity for ACS members to have input into the review process, before the new code was formally submitted to ACS management.

The new code of ethics was first presented to all ACS members in the April/May 2010 edition of Information Age.

\section{Structure of the new ACS code of ethics}

The various ACS codes described previously, namely the code of ethics, which comprised the values and ideals and the standards of conduct, and the separate code of professional conduct and professional practice have now been combined and rationalised. The new code of ethics is accompanied by two complementary codes: the code of conduct and the code of professional practice. 


\section{The code of ethics}

This is part of the ACS constitution, and describes six values to which professionals in the ICT industry are expected to adhere. When the final approval is given to the new code, the formal procedures for amending the constitution will be implemented and the existing code of ethics will be replaced with the new text.

\section{The code of conduct}

This is an expanded guide to how the code of ethics should manifest itself in the way members conduct themselves, and replaces the earlier material on professional conduct. This code is not part of the constitution and is, therefore, able to be amended by the ACS management committee on a majority vote. This is a public, and more explicit statement of how the ACS expects its members to conduct themselves.

\section{The code of professional practice}

This is a separate document that is yet to be reviewed and amended, but, for the time being, the existing document of that name remains in use, pending its replacement. The committee on computer ethics will take on the task of this review. The code of professional practice will have more practical examples of how the code of ethics is intended to operate in specific workplace situations.

\section{Summary of changes made}

All of the responses from the focus groups were considered and applied, although the specific recommended wording was changed in some cases, for consistency with other text, and to avoid duplication.

Environmental issues did not figure at all, let alone prominently, in the 1985 review. Now, environmental aspects have emerged as an issue that ACS members are concerned about and wish to have addressed in their code of ethics. Clauses on the environment were suggested in every focus group considering the current six ideals. This led the review team to consider the possibility of adding a new 'ideal' to do with environmental issues. No new clauses have been included, but the environmental consequences of using ICT have been mentioned in the preamble to the code, and in the value addressing public interest.

Similarly, in the 1985 review, issues related to women in the industry and as members of the ACS were not prominent, whereas, in the current review, one focus group session was entirely devoted to issues raised by women in the ACS, through the Director ACS-Women, concerning aspects of professional practice, particularly in relation to discrimination in the workplace. This focus group proposed five new clauses for the value relating to professionalism. Three of 
these have been combined in the new code, to maintain the spirit and intent of the original wording. The other two clauses were already covered by an existing, less specific clause.

Every clause was reviewed, and revised or deleted, as required. Other clauses were added to reflect the changed values. Other changes include:

- A preamble has been added to the code, and each value has an introductory paragraph.

- For consistency, only 'ICT' or 'information and communications technology' has been used.

- 'I must' has been changed to 'you will'. This makes the wording consistent with a regulation, it stresses an imperative, and is consistent with other international codes.

- 'Public' and 'public interest' have been used instead of 'community' as these words are used in Professions Australia's definition of a profession, and in other international codes. Also, some focus groups had concerns about the use and meaning of 'community'.

- 'Values and ideals' are now just 'values'. Some values have been changed to be actual values, and the new values are now:

- the primacy of the public interest

- the enhancement of quality of life

- honesty

- competence

- professional development

- professionalism

After each of the last two major revisions of the code of ethics, the ACS has published a one page summary of the values and ideals, known as the 'onepager'. An outcome of this renewal process will be a new version of the ACS values for distribution to all members. Given the above arguments for a business case, producing a new one-pager serves a dual purpose. Not only does it easily convey the main ideals upheld by the code of ethics, but it can also serve businesses. That is, it can be prominently displayed by businesses as a way of publicly aligning themselves with the professional values of the ACS, the peak professional ICT body in Australia. This link would be even stronger if, as suggested above, ICT businesses develop their organisational values and obligations to professionalism in close alignment with those of the ACS, and considered the benefits of the professional partner scheme.

This review process is significant to the wider ICT community as well. Just as the review process drew on similar work from the United States and the 
United Kingdom, so it is expected that the process will help inform other societies working through similar issues. The latter will be achieved through disseminating information about the process of the review through working groups of IFIP, a process that has already started, given four members of the CCE are IFIP working group members. More particularly, three are also members of the special interest group within one IFIP working group that is charged with the responsibility for developing frameworks on ethics, which has as one of its responsibilities the directive to help member societies to formulate their codes of ethics (IFIP SIG 9.2.2).

\section{Conclusion}

The greater the extent to which professional codes are kept current and relevant, the greater the business case for endorsing and promoting those codes.

In order to raise the profile of a code of ethics, one approach is to see the benefits to the organisation from a business perspective. As seen above in the pharmaceutical industry, such benefits include risk mitigation and the enforcement of professional and product standards. This argument can apply to many businesses, especially those that already have documented processes for running their operation. It has been argued above that an ethical and quality approach is consistent and complementary; they are two sides of the same coin.

Each professional society needs to ensure the currency of its code of ethics, through regular reviews, including major reviews every 10 years, and minor reviews taking place as required by significant technological advancements. A major review should involve an extensive consultation process, as advocated by IFIP, which claims that the 'process used to develop a code is as important as the code itself' (Berleur et al, 2004: 13). Revisions of the ACS code of ethics should ensure consistency between the various supplementary ACS codes; and rationalise the way that part of the code is incorporated into the national regulations to mandate its use, and the way that other parts of the code can be more easily updated.

The ACS is the guardian of professional ethics and standards in the ICT sector, and is committed to ensuring the beneficial use of ICT for all Australians. The code of ethics is the linchpin that enables the ACS to promote the value of professional conduct of its members to both consumers and suppliers. The ACS must take a leadership role in the marketing of the benefits of its professional Code to the ICT business community. 


\section{Acknowledgement}

The authors acknowledge the work of Philip Argy, past president of the ACS, who developed the original business case for the ACS code of ethics.

\section{References}

Association for Computing Machinery (ACM), 1999, Software engineering code of ethics and professional practice, version 5.2, viewed 5 January 2009, <http:// www.acm.org/about/se-code?searchterm=software+engineering + code + of + ethics+and+professional+practice $>$

Australian Council of Professions, 2009, Australian Council of Professions, viewed 5 January 2009, <http://www.professions.com.au/>

Berleur, J, Duquenoy, P, Holvast, J, Jones, M, Kimppa, K, Sizer, R \& Whitehouse, D, 2004, 'Criteria and procedures for developing codes of ethics or of conduct', IFIP Press, Laxenburg, Austria.

Bowern, ME, Burmeister, OK, Gotterbarn, D \& Weckert J, 2006, 'ICT integrity: bringing the ACS code of ethics up to date', Australasian Journal of Information Systems, vol 13, no 2, pp 168-81.

Burmeister, OK, 2000, 'Applying the ACS code of ethics', Journal of Research and Practice in Information Technology, vol 32, no 2, pp 107-20.

—, 2008, 'Introduction', in D McDermid (ed), Ethics in ICT: an Australian perspective, Pearson Education Australia, Frenchs Forest, NSW, pp 1-25.

\& Weckert, J, 2003, 'Applying the new software engineering code of ethics to usability engineering: a study of 4 cases', Journal of Information, Communication \& Ethics in Society, vol 3, no 3, pp 119-32.

Coldwell, J, 2008, 'Professional ethics and responsibilities', in D McDermid (ed), Ethics in ICT: an Australian perspective, Pearson Education Australia, Frenchs Forest, NSW, pp 277-302.

Davidson, P, 2004, 'ACS and IEAust jointly adopt software ethics, practice code', Information Age, April/May, pp 47-50.

Foley, K, Barton, R, Busteed, K, Hulbert, J, \& Sprouster, J, 1997, 'Quality, productivity and competitiveness: the role of quality in Australia's social and economic development', Wider Quality Movement. 
Gotterbarn, D, 1996, 'Establishing standards of professional practice', in C Meyer, ed, The responsible software engineer, Springer Verlag.

- 2000, 'Two computer-related codes', Perspectives on the Professions, vol 19, no 1 .

Lucas, R \& Weckert, J, 2008, Ethics and regulation in the ICT industry, report for the Australian Computer Society, Centre for Applied Philosophy and Public Ethics, Charles Sturt University, Canberra. 